\author{
Adrian NOSOL ${ }^{1}$ \\ Marian BARTOSZUK ${ }^{2}$ \\ Przemysław WINIARSKI ${ }^{3}$
}

\title{
BADANIA ENERGOCHŁONNOŚCI PROCESU TOCZENIA WSTECZNEGO COROTURN PRIME
}

\begin{abstract}
Powszechnie wiadomo, że pozycja wytwórcy części maszyn na rynku jest uzależniona od jakości i ceny produkowanych przez niego elementów. W celu obniżenia kosztów produkcji, a co za tym idzie zwiększenia swojej konkurencyjności przemysł maszynowy szuka energooszczędnych strategii obróbki. Jako przykład takiego podejścia można przytoczyć strategię toczenia wstecznego CoroTurn PRIME. Jednak nie każda nowość niesie ze sobą obniżenie kosztów wytwarzania. Z tego powodu autorzy postanowili zająć się tym zagadnieniem. Niniejszy artykuł przedstawia badania energochłonności toczenia wstecznego przeprowadzonego na tokarce konwencjonalnej. Badaniom poddano przypadek toczenia wykończeniowego.
\end{abstract}

Słowa kluczowe: toczenie, strategia obróbki, pobór mocy, toczenie wsteczne

\section{Wprowadzenie}

W dobie silnej konkurencji na rynku producentów części maszyn o pozycji przedsiębiorcy decyduje cena produktu i jego jakość. Aby zwiększyć konkurencyjność, poza utrzymaniem dobrej jakości produktu szuka się oszczędności, które można uzyskać dzięki zmniejszeniu energochłonności procesów. Realizuje się to głównie przez optymalizację ruchów maszyny (skrócenie drogi dojazdu narzędzia) oraz ograniczenie czasu operacji przezbrajania maszyny [5]. Obecnie poszukuje się nowych rozwiązań, związanych z minimalizacją poboru mocy. Bardzo energochłonne operacje technologiczne zastępuje się innymi, które nie wymagają tak dużego nakładu energetycznego. Jako przykład takich działań można podać zastępowanie operacji szlifowania przez nagniatanie [2]. Poszukiwanie nowych strategii obróbki może być nowym kierunkiem badań mających na celu zmniejszenie energochłonności procesów skrawania.

Warto zauważyć, że niedawno wiodący producent narzędzi skrawających wypuścił na rynek nową grupę narzędzi do toczenia, które umożliwiają prowa-

\footnotetext{
${ }^{1}$ Autor do korespondencji/corresponding author: Adrian Nosol, Politechnika Opolska, 45-272 Opole, ul. Sosnkowskiego 31, tel.: +48 77449 8672, e-mail: a.nosol@po.opole.pl

${ }^{2}$ Marian Bartoszuk, Politechnika Opolska, e-mail: m.bartoszuk@po.opole.pl

${ }^{3}$ Przemysław Winiarski, Politechnika Opolska, e-mail: winiarski.przemyslaw@gmail.com
} 
dzenie obróbki „wstecznej”. Według wskazań wytwórcy narzędzia te mogą pracować zarówno w układzie konwencjonalnym (toczenie od konika do uchwytu), jak i przy obróbce wstecznej (toczenie od uchwytu do konika). Ideę toczenia wstecznego pokazano na rys. 1 .

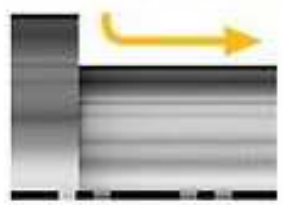

Do osi i od uchwytu (SBW)

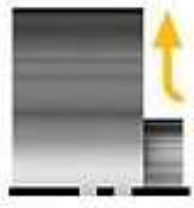

Do uchwytu i od osi (EBW)

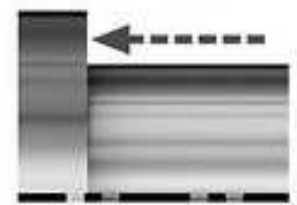

Wzdłużnie do uchwytu (SFW)

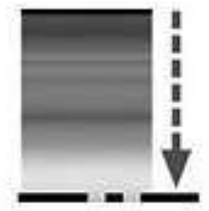

Promieniowo do osi (EFW)
Rys. 1. Graficzne porównanie kinematyki toczenia konwencjonalnego i wstecznego [3]

Fig. 1. Graphical comparison of kinematics of conventional and reverse turning [3]

Wielką zaletą tak prowadzonej obróbki jest oszczędność na przejazdach jałowych maszyny. W konsekwencji powinna się zmniejszyć ogólna energochłonność całego procesu. $\mathrm{Z}$ uwagi na fakt, że literatura nie podaje żadnych informacji dotyczących tego zagadnienia, autorzy postanowili zbadać ten aspekt. Ogólnie wiadomo, że w praktyce dominują trzy strategie obróbki toczeniem:

- toczenie ze stałą głębokością skrawania - przypadek toczenia konwencjonalnego,

- toczenie ze zmienną głębokością skrawania - przyczyniające się do zwiększenia trwałości ostrza,

- toczenie wsteczne (CoroTurn PRIME) - strategia wpływająca na zmniejszenie czasu trwania i energochłonności procesu oraz na polepszenie stereometrii powierzchni.

Strategia toczenia CoroTurn PRIME jest jeszcze nowym i mało znanym sposobem prowadzenia procesu obróbki. W związku z tym autorzy podjęli próbę oszacowania energochłonności tak prowadzonego procesu toczenia.

\section{Metodyka badań}

Do badań przyjęto przypadek toczenia konwencjonalnego narzędziem QS-CP-30AR-2020-11C wyposażonym w ostrze CP-A1104-L5 wykonane z węglika gatunku GC4325. Przyjęte do badań parametry skrawania zestawiono 
w tab. 1. Jako materiał obrabiany wybrano stal węglową konstrukcyjną AISI 1045 normalizowaną. Badania zostały zrealizowane na tokarce konwencjonalnej TUM-35D1 ze zmodernizowanym układem napędowym, zapewniającym elastyczną regulację prędkości skrawania. Usytuowanie próbki w przestrzeni roboczej maszyny pokazano na rys. 2 .

Tabela 1. Specyfikacja parametrów skrawania

Table 1. Specification of cutting parameters

\begin{tabular}{|c|c|c|c|}
\hline Nr próby & $f[\mathrm{~mm} / \mathrm{obr}]$ & $a_{p}[\mathrm{~mm}]$ & $v_{c}[\mathrm{~m} / \mathrm{min}]$ \\
\hline 1 & 0,1 & 0,5 & 170 \\
\hline 2 & 0,2 & 0,5 & 170 \\
\hline 3 & 0,28 & 0,5 & 170 \\
\hline 4 & 0,1 & 0,5 & 200 \\
\hline 5 & 0,2 & 0,5 & 200 \\
\hline 6 & 0,28 & 0,5 & 200 \\
\hline 7 & 0,1 & 0,5 & 230 \\
\hline 8 & 0,2 & 0,5 & 230 \\
\hline 9 & 0,28 & 0,5 & 230 \\
\hline
\end{tabular}

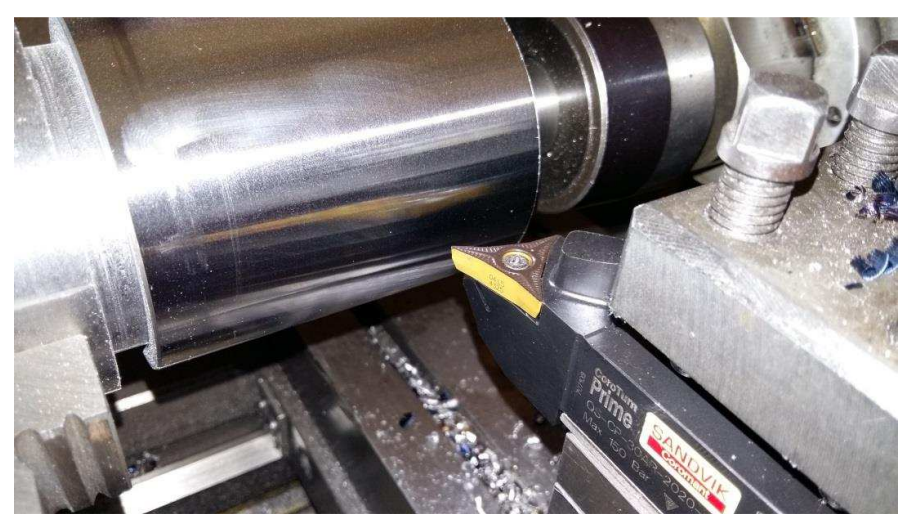

Rys. 2. Widok narzędzia i próbki w przestrzeni roboczej maszyny

Fig. 2. The view of the tool and sample in the machine working space

Pomiary konsumpcji energii prowadzono na torze pomiarowym własnej konstrukcji, zbudowanym na bazie przyrządu UT233 firmy UNI-T. Schemat ideowy toru pomiarowego przedstawia rys. 3 . W trakcie badań zbierano informacje o napięciu sieci zasilającej U, prądzie I pobieranym przez napęd główny maszyny oraz o wartości przesunięcia fazowego. Wartości energii pozornej, czynnej i biernej wyznaczano z obliczeń - zgodnie z ogólnie znanymi zależnościami. 


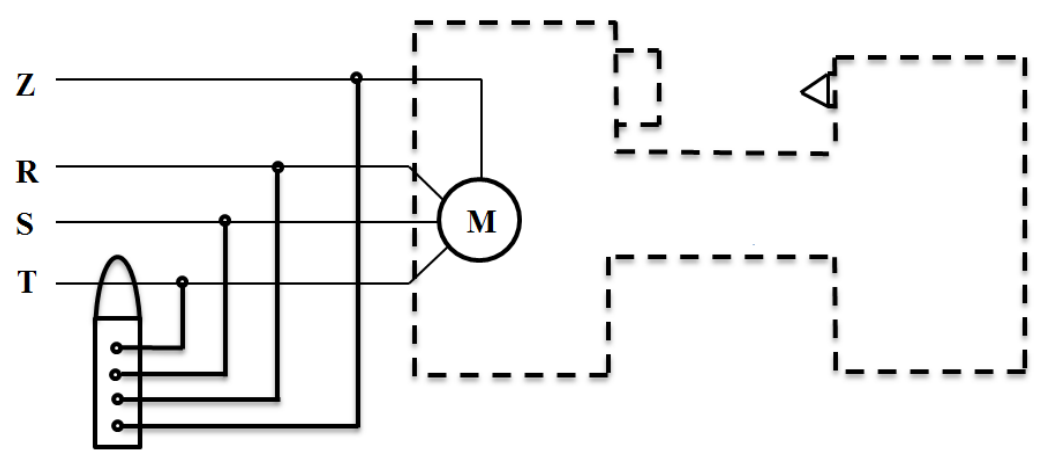

Rys. 3. Schemat toru pomiarowego

Fig. 3. The diagram of measurement system

\section{Wyniki badań i ich analiza}

Na podstawie przeprowadzonych badań otrzymano wyniki dla toczenia konwencjonalnego i wstecznego, ale dla parametrów obróbki zmiennych w tym samym zakresie. W tabeli 2 pokazano wyniki dla toczenia konwencjonalnego, natomiast w tab. 3 - dla toczenia wstecznego, uzyskane dla prędkości skrawania wynoszącej $200 \mathrm{~m} / \mathrm{min}$.

Tabela 2. Wyniki pomiarów dla toczenia konwencjonalnego; $v_{c}=200 \mathrm{~m} / \mathrm{min}$

Table 2. The measurement results for the conventional turning; $v_{c}=200 \mathrm{~m} / \mathrm{min}$

\begin{tabular}{|c|c|c|c|c|c|}
\hline $\begin{array}{c}f \\
\text { [mm/obr.] }\end{array}$ & $\begin{array}{c}\text { Moc czynna } \\
P \\
{[\mathrm{VA}]}\end{array}$ & $\begin{array}{c}\text { Moc bierna } \\
Q \\
{[\mathrm{Var}]}\end{array}$ & $\begin{array}{c}\text { Moc pozorna } \\
S \\
{[\mathrm{~W}]}\end{array}$ & $\begin{array}{c}R_{t} \\
{[\mu \mathrm{m}]}\end{array}$ & $\begin{array}{c}R_{a} \\
{[\mu \mathrm{m}]}\end{array}$ \\
\hline 0,10 & 2316,6 & 9,2 & 2316,8 & 8,25 & 1,23 \\
\hline 0,20 & 2947,9 & 2,9 & 2947,9 & 13,59 & 2,48 \\
\hline 0,28 & 3036,1 & 0,4 & 3036,1 & 25,20 & 4,92 \\
\hline
\end{tabular}

Tabela 3. Wyniki pomiarów dla toczenia wstecznego; $v_{c}=200 \mathrm{~m} / \mathrm{min}$

Table 3. The results of measurements for reverse turning; $v_{c}=200 \mathrm{~m} / \mathrm{min}$

\begin{tabular}{|c|c|c|c|c|c|}
\hline $\begin{array}{c}f \\
\text { [mm/obr.] }\end{array}$ & $\begin{array}{c}\text { Moc czynna } \\
P \\
{[\mathrm{VA}]}\end{array}$ & $\begin{array}{c}\text { Moc bierna } \\
Q \\
{[\mathrm{Var}]}\end{array}$ & $\begin{array}{c}\text { Moc pozorna } \\
S \\
{[\mathrm{~W}]}\end{array}$ & $\begin{array}{c}R_{t} \\
{[\mu \mathrm{m}]}\end{array}$ & $\begin{array}{c}R_{a} \\
{[\mu \mathrm{m}]}\end{array}$ \\
\hline 0,10 & 2293,7 & 23,9 & 2294,0 & 7,18 & 0,96 \\
\hline 0,20 & 2685,9 & 4,4 & 2685,9 & 12,25 & 2,35 \\
\hline 0,28 & 2957,2 & 3,4 & 2957,2 & 23,84 & 4,74 \\
\hline
\end{tabular}

Analizując otrzymane wyniki z obu tabel, można zaobserwować zgodny z przesłankami literaturowymi wzrost poboru mocy czynnej wraz ze wzrostem wartości posuwu, zarówno dla toczenia konwencjonalnego, jak i wstecznego 
[1, 4]. Analizując te same wyniki w formie graficznej, łatwo jednak zauważyć mniejszy pobór energii dla toczenia wstecznego w całym zakresie zmienności parametrów skrawania (rys. 4). Największą różnicę (ponad $250 \mathrm{VA}$ ) zaobserwowano dla posuwu $f=0,2 \mathrm{~mm} / \mathrm{obr}$. Różnicę tę można tłumaczyć nieliniowym charakterem zmian przebiegu konsumpcji energii.

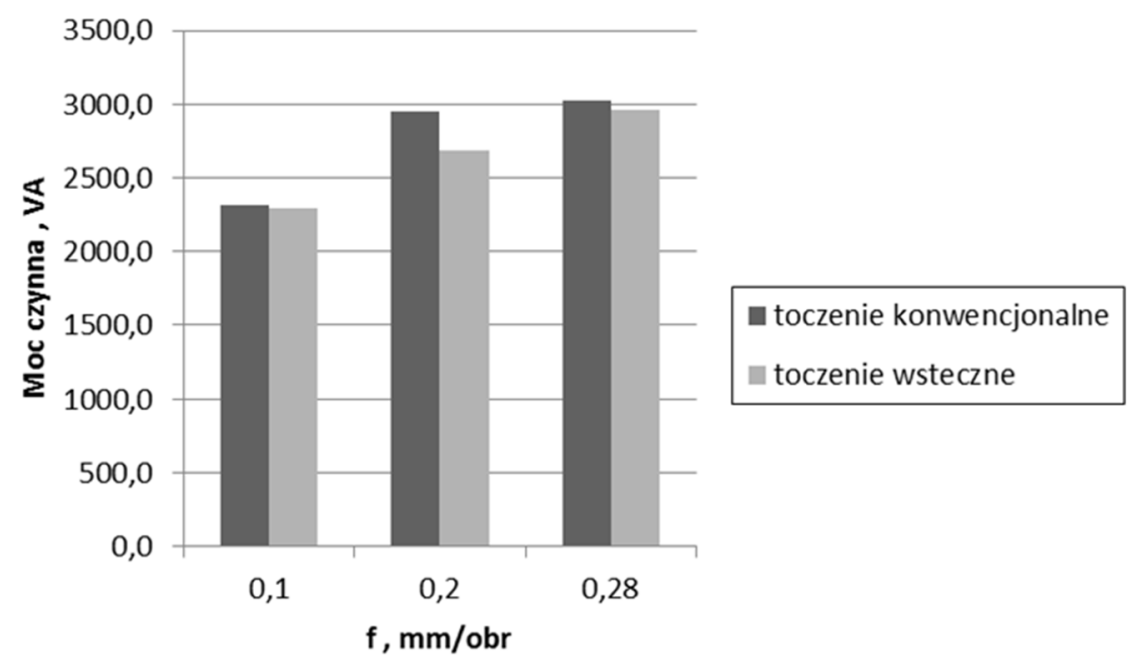

Rys. 4. Porównanie poboru mocy czynnej dla toczenia konwencjonalnego i wstecznego w funkcji posuwu

Fig. 4. The comparison of active power consumption for conventional and reverse turning as a function of feed

Z kolei analiza konsumpcji mocy biernej wykazuje o wiele bardziej widoczne różnice pomiędzy badanymi strategiami toczenia. Przy toczeniu wstecznym odnotowano znacząco większy pobór energii biernej niż przy toczeniu konwencjonalnym (rys. 5). Dla niektórych przypadków różnica wynosi nawet ponad $100 \%$. Na rysunku 5 zjawisko to ma miejsce dla posuwu $f=0,1 \mathrm{~mm} / \mathrm{obr}$. W przypadku obydwu badanych strategii obróbki, niezależnie od prędkości skrawania, zauważalny jest jednak spadek poboru mocy biernej wraz ze wzrostem obciążenia maszyny. Przy toczeniu wstecznym spadek poboru mocy biernej jest bardziej intensywny.

Warto również zauważyć, że przy takich samych parametrach obróbki toczenie wsteczne daje mniejszą wartość chropowatości powierzchni w całym badanym zakresie. Parametr $R_{a}$ dla toczenia wstecznego posiada mniejszą wartość niż przy toczeniu konwencjonalnym o około $10 \%$. Podobnie zmienia się wartość parametru $R_{t}$ - zmniejsza się o około $12 \%$. Zagadnienie to zobrazowano graficznie na rys. 6 . 


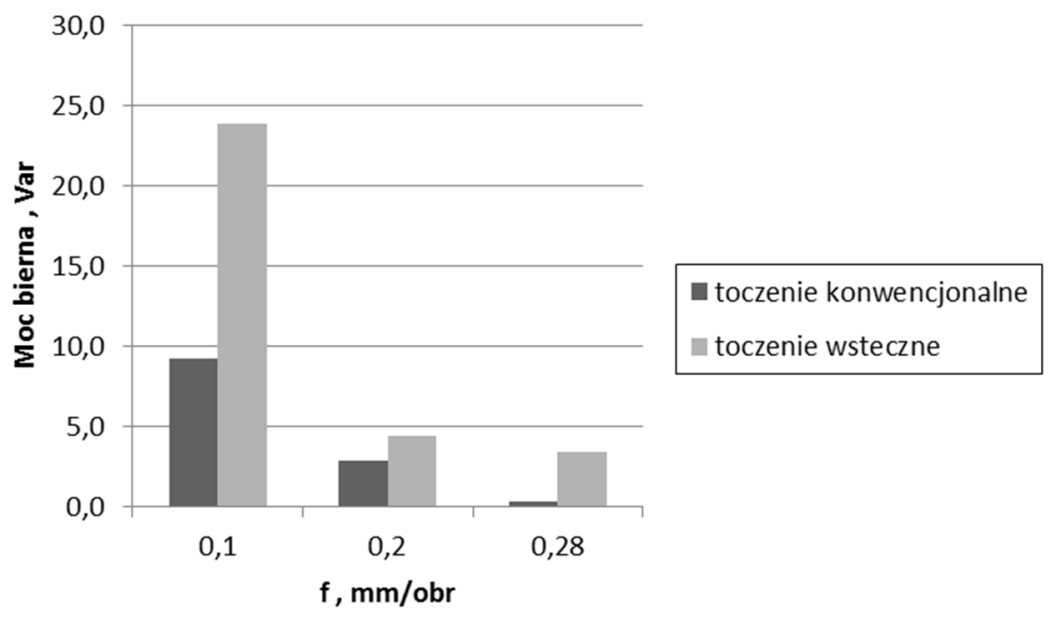

Rys. 5. Porównanie poboru mocy biernej dla toczenia konwencjonalnego i wstecznego w funkcji posuwu

Fig. 5. The comparison of passive power consumption for conventional and reverse turning as a function of feed

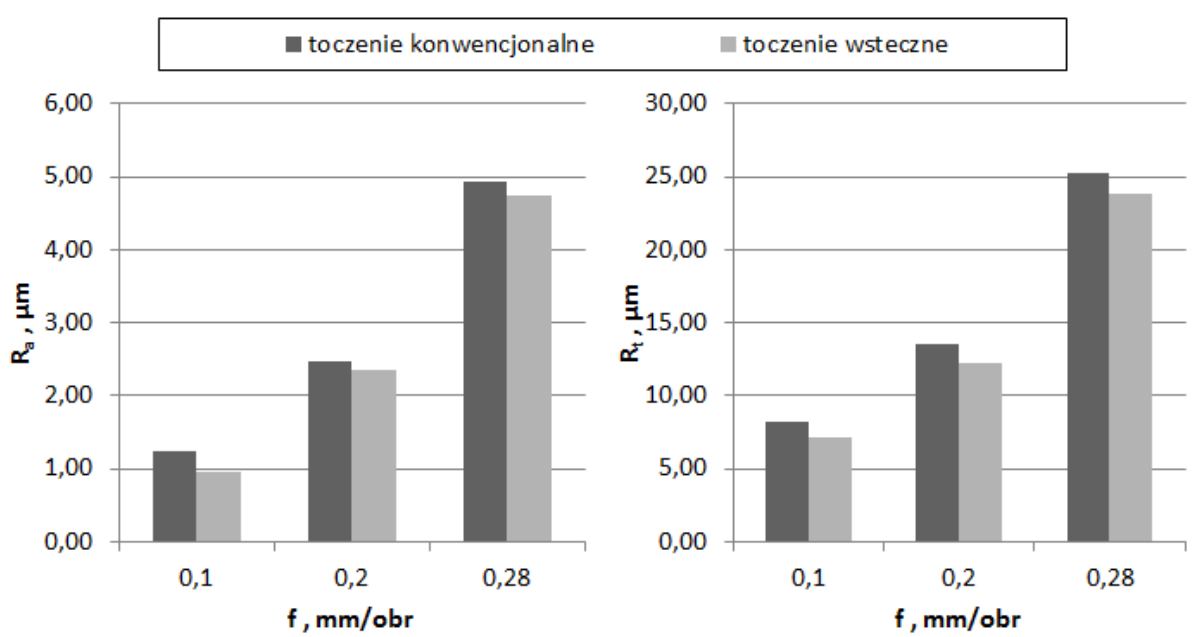

Rys. 6. Porównanie zmian chropowatości powierzchni dla toczenia konwencjonalnego i wstecznego

Fig. 6. The comparison of surface roughness changes for conventional and reverse turning

W świetle przedstawionych faktów łatwo zauważyć, że prezentowane wyniki stanowią jedynie wycinek szerszego założenia badawczego. Jednak już na ich podstawie można stwierdzić, że stosowanie nowych strategii obróbki może być doskonałym narzędziem optymalizacyjnym. W tym celu potrzebne są jednak dalsze szczegółowe badania dla szerszej zmienności parametrów skrawania oraz dla różnych materiałów obrabianych. 


\title{
4. Podsumowanie
}

Narzędziami CoroTURN Prime można toczyć konwencjonalnie i wstecznie, ograniczając $w$ ten sposób ruchy pomocnicze maszyny i skracając czas obróbki, a w konsekwencji zmniejszając energochłonność całego procesu. Odpowiednio dobrana dla danego procesu strategia obróbki może przynosić zatem wiele korzyści nie tylko pod względem ekonomicznym, ale również czasowym, wydajnościowym i ekologicznym. Przeprowadzone badania wskazują na możliwość opracowania strategii toczenia, która:

- przyczyni się do skrócenia czasu prowadzenia obróbki,

- wpłynie na bardziej racjonalne zużywanie energii przez minimalizację zapotrzebowania na energię bierną,

- spowoduje mniejszą konsumpcję energii całkowitej (pozornej) zużywanej w procesie produkcyjnym.

\section{Literatura}

[1] Carmita Camposeco-Negrete C.: Optimization of cutting parameters for minimizing energy consumption in turning of AISI 6061 T6 using Taguchi methodology and ANOVA, J. Cleaner Production, 53 (2013) 195-203.

[2] Chudy R., Grzesik W.: Investigation of sequential machining processes in terms of power consumption and surface quality, J. Machine Eng., 16 (2016) 67-74.

[3] http://www.sandvik.coromant.com (dostęp: 29 czerwca 2017 r.).

[4] Sealy M.P., Liu Z.Y., Zhang D., Guo Y.B., Liu Z.Q.: Energy consumption and modeling in precision hard milling, J. Cleaner Production, 135 (2016) 1591-1601.

[5] Terelak-Tymczyna A., Jardzioch A.: Analiza wpływu planowania procesu produkcyjnego na wykorzystanie maszyn oraz efektywność energetyczną, Mechanik, 89 (2016 ) 1306-1307.

\section{RESEARCH ON ENERGY CONSUMPTION OF REVERSE TURNING PROCESS COROTURN PRIME}

\begin{abstract}
S u m m a r y
It is well known that the position of the manufacturer of machine parts on the market depends on the quality and price of the components manufactured by them. In order to reduce production costs and thus to increase its competitiveness, the machine industry seeks energy-efficient machining strategies. As an example of this approach, CoroTurn PRIME reverse turning strategy can be cited. However, not every novelty brings with it a reduction in manufacturing costs. For this reason, the authors decided to explore this issue. This paper presents a study on the energy consumption of the reverse turning carried out on conventional lathe. This study involved a case of finishing turning.
\end{abstract}

Keywords: turning, machining strategy, power consumption, reverse turning

DOI: $10.7862 / \mathrm{rm} .2017 .32$

Otrzymano/received:12.07.2017

Zaakceptowano/accepted: 22.09.2017 
